\title{
Perinatal outcome of meconium stained amniotic fluid in pregnancy beyond 37 weeks
}

\author{
Joshi Suyajna D., Jayasakthi G.*, Rajeswari Rai, Ruksar Banu,
}

Department of DNB-OBG, District Hospital Ballari, Karnataka. India

Received: 03 December 2020

Revised: 06 January 2021

Accepted: 07 January 2021

\author{
*Correspondence: \\ Dr. Jayasakthi G., \\ E-mail: jayasakthi2411@gmail.com
}

Copyright: () the author(s), publisher and licensee Medip Academy. This is an open-access article distributed under the terms of the Creative Commons Attribution Non-Commercial License, which permits unrestricted non-commercial use, distribution, and reproduction in any medium, provided the original work is properly cited.

\begin{abstract}
Background: To identify the frequency of meconium aspiration syndrome among the total births who suffered from meconium staining of amniotic fluid, to find out risk factors during pregnancy, therapies and various complications associated with this condition and their effects on perinatal outcome.

Methods: This was a retrospective study of 252 antenatal patients delivered at Department of DNB-OBG District hospital Bellary during the year January 2019 to December 2019 with gestational age between 37-40 weeks with singleton pregnancies and cephalic presentation were included in the study.

Results: The Caesarean section rate for fetal distress was $96.6 \%$ in patients with meconium stained amniotic fluid (MSAF). Meconium aspiration syndrome (MAS) was found in $3.93 \%$ babies. APGAR score at 1 minute $<7$ was found in 25 cases $(9.84 \%)$.

Conclusions: Meconium stained amniotic fluid is associated with increased need for neonatal resuscitation, increased risk of birth asphyxia, meconium aspiration syndrome, hospital admission and mortality. So identification of pregnant woman at risk of passage of meconium during labour would allow intensive fetal surveillance and early intervention which might lead to reduction in neonatal adverse outcome.
\end{abstract}

Keywords: Foetal outcome, Meconium stained liquor

\section{INTRODUCTION}

Meconium-stained amniotic fluid is frequently encountered in obstetrics and neonatal practice. ${ }^{1}$ The word Meconium is derived from Greek word "meconium arion". 2

The incidence of meconium-stained amniotic fluid is 1$18 \% .^{3}$ It is seen in around $20-30 \%$ of all infants with meconium-stained amniotic fluid. In utero, passage of meconium may simply represent the normal gastrointestinal maturation or it may indicate an acute or chronic hypoxic event, thereby making it a warning sign of a fetal compromise. ${ }^{3}$
MAS occurs in about $5 \%$ of deliveries with meconium stained amniotic fluid and death occurs in about $12 \%$ of infants with MAS. ${ }^{4}$ Presence of meconium below vocal cord is known as meconium aspiration. ${ }^{5}$

Meconium passage is rare before 34 weeks of gestation and incidence increases steadily beyond 37 weeks of gestation. ${ }^{5}$ MSAF is associated with higher rate of cesarean delivery increased need for neonatal resuscitation and MAS. ${ }^{6}$ Aspiration can occur in utero with fetal gasping, or after birth, with the first breaths of life Meconium aspiration syndrome (MAS) is defined as a respiratory distress that develops shortly after birth, with radiographic evidence of aspiration pneumonitis and presence of meconium stained amniotic fluid. 
The objective of the study was to determine the perinatal outcome and mode of delivery in patients with meconium stained amniotic fluid during labour.

\section{METHODS}

The present study was retrospective observational study conducted in the Department of Obstetrics and Gynaecology, District Hospital Bellary from January 2019 to December 2019. All results were presented in tabular form.

In this study, all pregnant women with term pregnancy admitted to labour room who fulfilled the inclusion criteria and willing to participate were selected for the study. Feto maternal outcome were studied in meconium stained amniotic fluid pregnancies.

Data entry was done using Microsoft Excel and analysed using statistical package for social sciences (SPSS version 16). Categorical variables were summarized with $\mathrm{n}(\%)$. All the analysed data were presented in a tabular form.

In our study, pregnancy of gestational age >37 weeks, cephalic presentation, singleton pregnancies with no congenital anomalies were included and gestational age of <37 weeks, multiple pregnancy, noncephalic presentation like breech presentation, transverse lie and compound presentation were excluded.

On admission a detailed history was taken, clinical examination was performed and gestational age assessed. NST was performed for all patients. Parameters noted were MSAF, the mode of delivery, birth weight, Apgar score at 1 and 5 minutes. Results were analysed.

\section{RESULTS}

A total of 254 pregnant women who had completed more than 37 weeks of gestation, with singleton pregnancies and cephalic presentations, were included in this study. Among 254 cases with meconium stained amniotic liquor (MSAL), 60\% were unbooked and only $40 \%$ were booked (Table 1).

Table 1: MSAL and booking parameters.

\begin{tabular}{|lll|}
\hline Booking parameters & Numbers & Percentage \\
\hline Unbooked case & 152 & 60 \\
\hline Booked case & 102 & 40 \\
\hline
\end{tabular}

Table 2: Age and MSAL.

\begin{tabular}{|lll|}
\hline Age & Numbers & Percentage \\
\hline $\mathbf{2 0}$ & 15 & 5 \\
\hline $\mathbf{2 0 - 3 0}$ & 236 & 93.9 \\
\hline$>\mathbf{3 0}$ & 3 & 1.1 \\
\hline
\end{tabular}

$15.5 \%$ women were of $<20$ of age years $93.9 \%$ women were age-group of 20-30 years (Table 2).

Approximately $66.2 \%$ cases are primi, suggesting that meconium stained of amniotic fluid common in first gravida (Table 3).

Table 3: obstetric score and MSAL.

\begin{tabular}{|lll|}
\hline Gravida & Numbers & Percentage \\
\hline $\mathbf{1}$ & 170 & 66.92 \\
\hline $\mathbf{2}$ & 48 & 18.89 \\
\hline $\mathbf{3}$ & 13 & 5.11 \\
\hline $\mathbf{4}$ & 23 & 9.05 \\
\hline
\end{tabular}

Caesarean section was very commonly done in MSAF cases and it accounted for $98.42 \%$ cases. The results of mode of delivery and birth weight of babies were showed below in tabular form (Table 4 and 5).

Table 4: Mode of delivery.

\begin{tabular}{|lll|}
\hline Mode of delivery & Numbers & Percentage \\
\hline LSCS & 250 & 98.42 \\
\hline FTND & 4 & 1.57 \\
\hline
\end{tabular}

Table 5: Birth weight.

\begin{tabular}{|lll|}
\hline Birth weight & Numbers & Percentage \\
\hline $\mathbf{2 . 5}$ kg & 31 & 12.20 \\
\hline $\mathbf{2 . 5 - 3 k g}$ & 177 & 69.68 \\
\hline$>$ 3kg & 46 & 18.11 \\
\hline
\end{tabular}

Table 6: Perinatal outcome.

\begin{tabular}{|lll|}
\hline Perinatal & Numbers & Percentage \\
\hline Asymptomatic at birth & 130 & 51.18 \\
\hline Apgar score at 1 min $<7$ & 25 & 9.84 \\
\hline Apgar score at 5 min <7 & 19 & 7.48 \\
\hline MAS & 10 & 3.93 \\
\hline $\begin{array}{l}\text { Birth asphyxia fetal } \\
\text { bradycardia }\end{array}$ & 70 & 27.55 \\
\hline
\end{tabular}

Table 7: Consistency of meconium stained.

\begin{tabular}{|lll|}
\hline Consistency & Numbers & Percentage \\
\hline Thick & 43 & 16.92 \\
\hline Thin & 211 & 83.07 \\
\hline
\end{tabular}

A total $27.55 \%$ cases had foetal heart rate abnormalities which were detected by electronic foetal monitoring and presence of foetal bradycardia was statistically higher. The results of the study were presented in a tabular form (6 and 7) below. In 51.18\% cases, babies were asymptomatic at birth. $9.84 \%$ of infants with MSAF had low Apgar scores at birth and $27.55 \%$ cases needed intensive care unit admissions. Meconium aspiration was seen in 10 cases. 


\section{DISCUSSION}

This study was done to find out the fetal outcome of those deliveries where liquor was meconium stained and to determine the risk of adverse fetal outcome associated with meconium stained amniotic fluid. In our study the average age of patients was 21-24 years of age Rajlaxmi et al also had similar results. Mode of delivery was significantly influenced by the presence of meconium stained amniotic fluid. In our study caesarean deliveries were high $(75 \%)$ in cases. In spite of debate, most obstetricians feel unsafe about the state of foetus, if the amniotic fluid is meconium stained during labour. This has influenced the mode of delivery a lot. Even in places where other facilities of intrapartum monitoring like fetal blood sampling and cardiotocography are available, the rate of caesarean delivery were found to be increased. Birth asphyxia was significantly high in thick meconium stained amniotic fluid. Requirement of oropharyngeal suction was significantly more in cases. Meconium aspiration syndrome was developed in 10 cases. Among them it was significantly higher in thick meconium stained. It might be due to the fact that meconium aspiration syndrome was primarily associated with acute hypoxic events late in labour or often a chronic prenatal disease related to acute events that occur late in labour or after birth and also depends on increasing consistency of meconium.

Limitation of the study: The study has certain limitations. As our study was a retrospective observational study, some key statistics could not be measured and also as retrospective study is known to analyse pre-existing data and are subjected to numerous biases, we could not control the exposure or outcome assessment and instead we had to depend on others for accurate record keeping.

\section{CONCLUSION}

Meconium-stained amniotic fluid is associated with increased need for neonatal resuscitation, increased risk of birth asphyxia, meconium aspiration syndrome, hospital admission and mortality. So, identification of pregnant woman at risk of passage of meconium during labour would allow intensive fetal surveillance and early intervention which might lead to reduction in neonatal adverse outcome.

Funding: No funding sources

Conflict of interest: None declared

Ethical approval: The study was approved by the Institutional Ethics Committee

\section{REFERENCES}

1. Mesumbe EN, Nana PN, Nouetchognou JS, Dohbit JS, Mah E, Eko FE. Perinatal Outcome in Term Pregnancies with Meconium Stained Amniotic Fluid in Two Referral Hospitals of Yaoundé-Cameroon. Journal of Scientific \& Technical Research. 2018;2(2):2533-7.

2. Vaghela HP, Deliwala K, Shah P. Fetal outcome in deliveries with meconium stained liquor. International Journal of Reproduction, Contraception, Obstetrics and Gynecol. 2017;3(4):909-12.

3. Qadir S, Jan S, Chachoo JA, Shameem P. Perinatal and neonatal outcome in meconium stained amniotic fluid. Into J Repro'd Contraceptive, Obstet and Gynecol. 2016;5(5):1400-5.

4. Mundhra R, Agarwal M. Fetal outcome in meconium stained deliveries. Journal of clinical and diagnostic research: JCDR. 2013;7(12):287.

5. Khatun MH, Arzu J, Hague E, Kamal MA, Al Mamun MA, Khan MF, et al. Fetal outcome in deliveries with meconium stained liquor. Bangladesh Journal of Child Health. 2009;33(2):41-5.

6. Khillan S, Dahra J, Kaur P. Adverse perinatal outcome and mode of delivery in patients with meconium stained amniotic fluid. Heart Disease. 2018; 14:2-1.

Cite this article as: Joshi SD, Jayasakthi G, Rai R, Banu R. Perinatal outcome of meconium stained amniotic fluid in pregnancy beyond 37 weeks. Int $\mathrm{J}$ Reprod Contracept Obstet Gynecol 2021;10:624-6. 